\title{
Orbivirus Infection
}

National Cancer Institute

\section{Source}

National Cancer Institute. Orbivirus Infection. NCI Thesaurus. Code C36066.

An infection that is caused by Orbivirus. 